\title{
CORRESPONDENCE
}

\section{The Diagnosis and Treatment of Hemoptysis}

by PD Dr. med. Harald Ittrich, Prof. Dr. med. Maximilian Bockhorn, Dr. med. Hans Klose, and Dr. med. Marcel Simon in issue 21/2017

\section{Particularities of Goodpasture Syndrome}

The article outlines the invasive therapeutic options for the treatment of hemoptysis (1). However, in my view, the peculiarities of hemoptysis treatment in Goodpasture syndrome should be at least briefly discussed (2). Although this syndrome is rare, hemoptysis is often the main acute threat to the patient's life and is an urgent indication for removal of the pathogenic anti-basement membrane antibodies by plasmapheresis. As the target antigen of the antibody (the non-collagenous domain of the alpha 3 chain of type IV collagen) is accessible both in alveolar as well as in glomerular basement membranes, and as hemoptysis can be induced in animals using anti-basement membrane antibodies (3), there should be little doubt about the pathogenetic role of the antibodies. This importance of these antibodies seems to be also demonstrated by the observation that hemoptysis sometimes stops during plasmapheresis, although of course drugs such as cyclophosphamide, prednisolone, and perhaps rituximab are indispensable for the permanent control of the clinical picture $(2,4)$. DOI: 10.3238/arztebl.2017.0662a

\section{REFERENCES}

1. Ittrich H, Bockhorn M, Klose H, Simon M: The diagnosis and treatment of hemoptysis. Dtsch Arztebl Int 2017; 114: 371-81.

2. Clark WF, Huang SS, Walsh MW, Farah M, Hildebrand AM, Suntrop JM: Plasmapheresis for the treatment of kidney diseases. Kidney Int 2016; 90: 974-84.
3. Reynolds J, Moss J, Duda MA, Smith J: The evolution of crescenting nephritis and alveolar hemorrhage following induction of autoimmunity to glomerular basement membrane in an experimental model of Goodpasture's disease. J Pathol 2003; 200: 118-29.

4. Goto K, Nakai K, Fujii H, Nishi S: The effects of plasma exchange on severe vasculitis with diffuse alveolar hemorrhage. Int Med 2017; 56: 55-9.

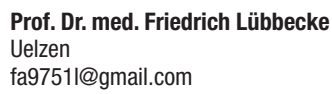

\section{Conflict of interest statement}

The author declares that no conflict of interest exists.

\section{In Reply:}

We thank the reader for his helpful comment and detailed remarks about the treatment of hemoptysis in Goodpasture syndrome. However, this is a rare cause of hemoptysis, with an incidence of $0.2 \%$, for which reason we did not elaborate on the specific therapies in our review (1). As with other pathologies, special diseases require special therapies, as this clinical picture impressively highlights.

DOl: 10.3238/arztebl.2017.0662b

\section{REFERENCES}

1. Ittrich H, Bockhorn M, Klose H, Simon M: The diagnosis and treatment of hemoptysis. Dtsch Arztebl Int 2017; 114: 371-81.

On behalf of the authors:

PD Dr. med. Harald Ittrich

Department for Diagnostic and Interventional Radiology

Center for Radiology and Endoscopy, University Medical Center HamburgEppendorf

ittrich@uke.de

Conflict of interest statement

PD Dr. Ittrich has received conference fee reimbursement, travel expenses, and speaking honoraria from Boston Scientific. 